\title{
Uterine Rupture
}

National Cancer Institute

\section{Source}

National Cancer Institute. Uterine Rupture. NCI Thesaurus. Code C128716.

The complete, nonsurgical disruption of all layers of the uterus. 